\title{
Analysis of Condolence Response to the Death of Dr. John Pombe Joseph Magufuli on Facebook
}

\author{
Phaustini B. Bayo \\ ORCID: https://orcid.org/0000-0002-5102-346X \\ Department of Business Management \\ Moshi Co-operative University, Tanzania \\ Corresponding Mail: bayophaustin@gmail.com
}

\begin{abstract}
Copyright resides with the author(s) in terms of the Creative Commons Attribution CC BY-NC 4.0. The users may copy, distribute, transmit and adapt the work, but must recognize the author(s) and the East African Journal of Education and Social Sciences
\end{abstract}

\begin{abstract}
This study investigated on condolence comments posted on Facebook pages in response to the death of the fifth president of the United Republic of Tanzania, Dr. John Pombe Joseph Magufuli. A total of $\mathbf{2 0 0}$ comments were extracted from famous Facebook accounts. The findings revealed seven strategies of giving condolences from the most frequently used to the less frequently used: asking for God's mercy and forgiveness, commenting on the deceased, expressing shock and grief, expressing sympathy, realizing death as a natural part of life, expressing skepticisms and reciting some verses from Holy books like the Bible and Quran. The choice of these strategies was related to respondents' belief in either Christian or Islamic religion, the status of the deceased before death and nature and contribution offered by the deceased to other people's life before his death. It is recommended that we should significantly contribute to other people's life in one way or another so that we can be remembered here on earth at the end of our life like the way Magufuli was and is still remembered because of his good deeds and the significant contributions he offered to other people's life before his death.
\end{abstract}

Keywords: Condolences; speech acts; responses; and Facebook, Magufuli.

How to cite: Bayo, P. B. (2021). Analysis of Condolence Response to the Death of Dr. John Pombe Joseph Magufuli on Facebook. East African Journal of Education and Social Sciences 2(4), 111-118. Doi: https://doi.org/10.46606/eajess2021v02i04.0134.

\section{Introduction}

One of characteristics that distinguish people from animals is ability to use language. Language is unique to humans in the sense that it is used to convey information from one person to another, to express opinions, to convey feelings and to ask for clarification (Gee, 1993). Language as a means of communication is also used to express condolence when one dies. While death is considered as a natural part of life, it is difficult to handle it because it is considered as a permanent loss of someone (Holt 1993). In this case, condolence utterances are employed to encourage, support and comfort individuals, groups and communities that have lost their people.

Condolences are expressed differently from one language to another due to differences in the way death is perceived and handled. For instance, in one speech community, the accepted ways of expressing condolences may be by sending a sympathy card supported with tokens such as money given to the bereaved but in other cultures there may be different ways of consoling with someone who has lost his/her dearest person. Zunin and Zunin (2007) described that condolence utterances exhibit certain implicit meaning which varies from culture 
to culture. Thus, condolers need to be aware of the beliefs and values when expressing condolences to people who are different from their own culture. In the same vein, Dawlatabadi and Mashhadi (2019) emphasized that in giving correct and appropriate condolences, speakers need to consider the belief system and cultural background of the bereaved.

In expressing condolences, speakers are required to be careful because of the sensitive nature of death; the language used in conveying condolence messages needs to be carefully chosen and offered in appropriate emotions and tone based on the culture of the deceased. In the same view, Nurlianingsih and Imperian (2019) asserted that the language used in normal conversation is different from the one used in such emotional situations like death. This makes giving condolences to be a challenging issue to many people. In this case, condolers should at least carefully figure out their messages of condolence while relying on different linguistic devices and delivering it with appropriate emotions to enable the grieved and other mourners to endure the loss. Al-shboul and Maros (2013) emphasized that speakers should prudently choose their words and skillfully phrase them when giving condolences so as to encourage the bereaved to return to their normal life.

Scholars have identified various strategies of giving condolences in different languages. Most of the identified condolences strategies seem common across the investigated languages while others appear to be specific to a particular language. These strategies include among others, acknowledging the death, expressing sympathy, the offer of assistance, future-oriented remark, expression of concern, seeking absolution from God, and related strategies (Elwood, 2004; Behman, Hamed \& Asli, 2012; Moghaddam, 2012). While some strategies appear common across the investigated languages, their uses differ from one language to another. Most strategies seem to be more frequently used in one speech community and less frequently in another. Therefore, appropriate expression of condolence messages depends on effective use of strategies employed based on the cultural context of the bereaved.

While most of the previous contributions have concentrated on other types of speech acts like requests, complaints, refusal, greetings and apologies, little attention has been given to speech act of giving condolences. This calls for more studies to be conducted. Most of the previous studies have investigated the speech of giving condolences in other languages than Kiswahili (Nurlianingsih and Imperian, 2019; Al-Shboul and Maros, 2013; Moghaddam, 2012. Therefore, this study examined condolence strategies used in response to the death of Dr. John Joseph Magufuli using Kiswahili Language on Facebook.

\section{Review of Literature}

\section{Theoretical Framework}

This study was guided by the politeness theory developed by Brown and Levinson (1987). Politeness theory was built around three basic concepts. These concepts are: face, face - threatening acts, and politeness strategies. The authors defined face as a public self-image that an individual uses to maintain interaction with others. It comprises of two parts: positive face and negative face. Positive face is considered as person's want that his or her desires be admired, supported and at least desirable to other people in the community. Negative face, on the other hand, is attributed to a person's want to be free from other people's imposition and destruction (Brown and Levinson 1978; Scollon \& Scollon 1995).

Face-threatening acts are considered as communicative behaviors that cause threat to one's expectations regarding his or her face (Yule, 1996). They are acts that naturally affect addressee's or speaker's self - image (Brown and Levinson 1978). The acts that inherently affect the addressee's positive or negative face are criticisms, complaints, accusations, offers, and promises while those that affect either speaker's positive or negative face include apologies, accepting a thank-you, confession and expressing gratitude (Brown and Levinson 1978).

Most of the speech acts identified by Brown and Levinson (1987) are naturally threat to either addressee or speaker's positive face. In the same vein, Williams (2006) argued that expressing condolences is one of the acts that threaten the face of the bereaved. To mitigate the FTAs, Brown and Levinson (1987) developed three strategies. These strategies are: negative politeness, positive politeness and both positive and negative politeness. Negative politeness is concerned with redressing the hearer's negative face, his/her basic needs to maintain the hearer's freedom of action while positive politeness is concerned with 
supporting and encouraging the hearer's positive face.

Politeness theory is relevant since it satisfies the needs of this study. The theory proposes that among multiple responses of giving condolences, a speaker needs to carefully select the best strategy in an attempt to serve the hearer's face need. Therefore, expressing the appropriate and accepted condolence messages is considered as polite way of encouraging those who have lost their loved ones.

\section{Empirical Review}

Elwood (2004) studied a cross-cultural analysis of giving condolences between English and Japanese using 75 respondents: 25 Japanese students filled the discourse completion test in English, 25 filled it in Japanese language while 25 who were English wrote the text in English. The data were collected through discourse completion test from two different unhappy situations: the situation related to the death of a pet dog and the death of a grandmother. The findings revealed five strategies of expressing condolences: expressing sympathy, acknowledging the death, the offer of assistance, expression of concern, and future-oriented remark. Elwood's analysis also shows that there was a significant variation between the death of a pet dog and the death of a grandmother. Finally, the study concludes that the condolence situation differs from one to another and therefore results cannot be generalized to other similar situations.

Another comparative study was conducted by Behman, Hamed and Asli (2012) who investigated strategies of giving condolences between English and Persian. The participants were 30 Persian people and 30 English people who responded to the discourse completion test sent to them via e-mail. The results depicted eight strategies of giving condolences which are religious expression, expression of surprise, offering assistance, apologetic expression, questions concerning the deceased, expressing sympathy, direct condolence and remarks about the future. Persian condolence messages were short, direct and were affiliated with the religious background while English condolence messages seemed apologetic, sympathetic and indirect.

In the Jordanian context, Al-Sboul and Maros (2013) investigated condolence strategies in Jordanian Arabic expressed through Facebook. The data were gathered from posted comments on Facebook. A total of 678 comments was analyzed to identify sociolinguistic strategies used to express condolences. The study revealed eight strategies of expressing condolences which are: reciting Quranic verses, forgiveness for the deceased, praying for God's mercy, expressing shock and grief, enumerating the virtues of the deceased, realizing death is a natural part of life, offering condolences, and using proverbs and sayings. The uses of these strategies were governed by respondents' religious background beliefs.

In Africa, Egenti and Mmadike (2016) studied the speech act of Igbo utterances used during funeral rites in Igbo-speaking land in Nigeria. In their study, they observed that in Igbo, it is customary to bury the dead person following the burial rites. They maintain that during the process, there are condolence messages addressed to the deceased, to God, to the deceased's family and relatives, to the deceased's friends and to the in-laws. These condolence messages are offered to express sympathy to the bereaved, to comfort and condole the grieved by encouraging them to pay last deference to the deceased, to express gratitude for the deceased's legacies and to pray for the deceased's soul to rest in peace.

Nurlianingsih and Imperian (2019) studied strategies used by Indonesian adolescents in giving condolences in different life situations and the effect of power and distance on the choice and use of those strategies. Based on Elwood's (2004) categorization of condolences strategies and Brown and Levinson's (1987) politeness theory, the researchers were able to classify responses into seven strategies arranged from the most frequently used to less frequently used. The strategies include: acknowledging the death, expressing sympathy, the offer of assistance, future-oriented remarks, expression of concern, seeking absolution from God, and related questions. The study revealed that power and distance affect the choice of condolence strategies since the difference in the use of strategies was influenced by the relationship between the condoler and the bereaved. Therefore, when the power is symmetrical and individuals are aware of each other, then the respondent uses higher risk strategies but when the power is asymmetrical and individuals are not so familiar with one another, then the respondent uses lower risk strategies.

The literature reviewed shows that there is a deficiency of studies conducted on the speech act of giving condolences in the Tanzanian context, Swahili 
language in particular. Most of the studies were conducted in Europe, America and Asia. Therefore, this study intended to investigate the speech act of giving condolences in Kiswahili. The study specifically examined sociolinguistics strategies of giving condolences expressed to obituary status on Facebook pages to the death of Dr. John Pombe Magufuli who was the fifth president of the United Republic of Tanzania.

\section{Research Methodology}

\section{Research Design}

This study used a case study design which allows data to be collected at a time and from a particular social context. The design is convenient in studying a community, a social group, an organization, an event, a system, a personality and even a single person (Walliman, 2006). In this case, a case study design was very significant since it helped to collect the data from the past event on written condolences' comments posted on Facebook pages during national mourning for the late president Dr. John Joseph Pombe Magufuli. The study was qualitative in nature (Hancock, Windridge \& Ockleford, 2009).

\section{Sampling Techniques}

Purposive sampling was employed to get the required responses. Singh (2006) asserts that purposive sampling aims at getting the sample based on some features which are considered significant for a particular study. The researcher considered only relevant condolences' comments expressed in Kiswahili. Moreover, gender was considered as it affects language use, in the sense that women tend to use more polite language than men (Coates, 2015). The researcher was able to collect 100 condolence comments from names that reflect male gender and the other 100 condolences comments from names that reflect female gender. In this case, a total of 200 condolence comments were selected as a sample. Names that can be used by both males and females were not included in the sample because it was difficult to recognize the gender of a person.

\section{Data Collection Procedure}

Data were collected through documentary review. These documents were downloaded from a famous website on Facebook that contained condolence comments offered to obituary status posted on Facebook pages as a result of the death of the president Dr. John Pombe Joseph Magufuli. The documents were then reviewed because they were considered to contain the required condolences comments in written forms. Facebook was chosen because it is among the leading social media in Tanzania in terms of users.

In 2012, the number of Facebook users in Tanzania was approximately 682,000 people and it was expected to increase by 56,580 people after every six months (Pfeiffer, Kleeb, Mbelwa, and Ahorlu, 2014). Currently, the statistics show that there is a total number of 12.4 million users of social media in the country of which Facebook users are estimated to be $5,223,000$ people (World Bank, 2020). The statistics further show that the main users of Facebook are youths with an age range of 15 to 30 years old. On the other hand, the data depict that the use of Facebook in Tanzania is gender- based with $29 \%$ of female users and $71 \%$ of male users (Pfeiffer, Kleeb, Mbelwa, and Ahorlu, 2014). These make Facebook to be an interesting social networking website to collect data with.

\section{Data Analysis}

After transcribing the data from Kiswahili to English, the analysis adopted Newman (2014) approach of coding qualitative data. Firstly, the researcher carefully read through the data to have an understanding of the given condolences comments while partially assigning the set of codes. Secondly, the researcher went through the condolence comments again while assigning more detailed codes. Thereafter, he grouped similar kinds of condolence comments in categories. Finally, the researcher identified and arranged the themes from most frequently occurring to less frequently occurring. Therefore, six major categories were identified: asking for God's mercy and forgiveness, commenting on the deceased, expressing shock and grief, expressing sympathy, realizing death as a natural part of life and reciting some verses from Holy books.

The researcher requested one autonomous language scholar to assign codes to the given data to ensure the provided condolence comments fit into the coding frame developed by the researcher. The language scholar had knowledge and experience in coding qualitative data. After the coding was done, some minor differences were observed which were resolved through discussion and agreement. The final categories are asking for God's mercy and forgiveness, commenting on the deceased, expressing shock and grief, expressing sympathy, expressing skepticism, realizing death as 
a natural part of life and reciting some verses from Holy books. The frequency for each condolence's strategy is shown in Table 2.

\section{Results and Discussion}

The analysis was guided by the following research questions:

1. What are the most frequently used strategies of expressing condolences in Kiswahili?

2. What are the factors that govern the choice of those strategies?

\section{Strategies Used in Giving Condolences}

The analysis has depicted seven strategies employed in expressing condolences in Kiswahili as portrayed in Table 2. The condolences strategies in Table 2 are arranged based on the frequency and percentages of their uses, that is, from the most frequently preferred strategies to less frequently used strategies. Among the seven strategies of giving condolences, asking for God's mercy and forgiveness appears to be the most frequently used while reciting some verses from Holy books seems to be the less frequently employed strategy.

Table 2: Strategies employed in expressing condolences

\begin{tabular}{lcc}
\hline \multicolumn{1}{c}{ Strategy } & Frequency & Percentage \\
\hline Asking for God's Favour and God's Forgiveness & 92 & 46 \\
Commenting on the deceased & 45 & 22.5 \\
Expression of Shock and grief & 21 & 10.5 \\
Expressing Sympathy & 18 & 09 \\
Realizing death as a natural phenomenon & 13 & 6.5 \\
Expressing Skepticism & 07 & 3.5 \\
Reciting verses from Holy books & 04 & 02 \\
Total & $\mathbf{2 0 0}$ & $\mathbf{1 0 0}$ \\
\hline
\end{tabular}

\section{Asking for God's mercy and God's forgiveness}

Table 2 shows that 'praying for God's mercy and forgiveness ranked the first among the seven strategies of giving condolences with $46 \%$ of all the responses. The most preferred expression under this strategy was Mungu ailaze roho ya marehemu mahala pema peponi (may God rest the deceased's soul in peace). This response shows condolers' strong belief in divine authority (God) having control over people's soul. The effective use of this strategy seems to comfort and encourage the bereaved with the hope that when they pray to God for the forgiveness of deceased' sin, God will forgive and grant his mercy for the deceased's soul to rest in peace. This finding is similar to that of Nurlianingsih and Imperiani (2019) as they reported that most of the responses offered by participants in their study seem to seek absolution from God. This is, however contrary to some other faiths that do not believe in the soul of the dead resting in eternal peace.

\section{Commenting on the Deceased}

The statistics in Table 2 revealed that comment on the deceased ranked the second with $22.5 \%$ of all the responses. The most repetitive expression under this strategy is tutakukumbuka daima (we will remember you forever'). Most respondents used this strategy as a way of reflecting on the significant contributions offered to them by the deceased in all spheres of life before his death. Though he had died, his good deeds would always be remembered. Moreover, this strategy was employed to maintain the face need of the bereaved since what is remembered is only the good acts done by the deceased before his departure. To this end, condolence is uttered to encourage, comfort and console the grieved. This result is in harmony with Al-Shboul and Maros (2013) where most condolence expression offered by the respondents in their study was related to enumerating the virtues of the deceased. The reason for employing this strategy was related to participants' strong beliefs on Islamic religion since the study was conducted in Jordan where the highest population of people is Muslims with $92 \%$.

\section{Expressing Shock and Grief}

Based on the data in Table 2, expressing shock and grief appeared to be the third strategy having $10.5 \%$ of the total responses. The dominant expression employed in this strategy was dah! inauma sana jamani ("dah! it is so painful"). This shows that death is something that is unexpected and when it happens it hurts people. Therefore, this strategy is used to show that not only the concerned family and relatives but also others are deeply touched by the death of the loved one. 


\section{Expressing Sympathy}

As indicated in Table 2, expressing sympathy ranked the fourth strategy consisting of $9 \%$ of all the given condolence comments. It is common for people to show sympathy to the bereaved as a way of portraying solidarity when something bad has happened. Among others, tunatoa pole kwa familia ya Magufuli (We convey our sympathy to Magufuli's family) appears to be the most frequently used expression. This result is similar to that of Yahya (2010) who found expression of sympathy as among the dominantly employed strategies of giving condolences among the Iraqi Arabic people. Yahya's study revealed that the use of sympathy was strongly influenced by sex in the sense that women tended to use more strong emotional words when expressing condolences compared to men.

\section{Realizing Death as a Natural Part of Life}

The finding revealed that realizing death as a natural part of life ranked fifth with $6.5 \%$ of all the responses. One of the most frequent expressions used under this strategy was kila nafsi itaonja mauti (every soul will taste death). The respondents perceive death as a natural part of life and thus, no one will escape. This finding is in line with Williams (2016) who found that most responses in her study were related to acknowledging death as a natural part of life. The reason for the use of the strategy was related to people's conscience.

\section{Expressing Skepticism}

Table 2 indicates that expressing skepticism appears to be the six strategy with $3.5 \%$ of the total responses. The most recursive responses under this strategy was duh mpaka sasa siamini kama kweli katutoka raisi wetu (duh up to this moment, I don't believe if it is true that our president has departed). This response revealed the respondents' disbelief in the act that happened. Though they had heard the news about the death of their president, they still doubted and sometimes denied the reality. Expression of skepticism was used to show how important the deceased was before his death not only to his family but also to other mourners.

\section{Reciting Verses from Holy Books}

Reciting some verses from Holy books like Bible and Quran become the last among the seven strategies of expressing condolences with $2 \%$ of all the responses. Bwana alitoa na Bwana ametwaa, jina la Bwana libarikiwe (The Lord gave, and the Lord has taken away, blessed be the name of the Lord) appears to be the most dominant expression under this strategy. This response shows that God is the source of human life and he can take back one's soul; therefore, death is something beyond human ability to prevent. The use of this strategy is attributed to respondents' belief that the Holy books are guidelines to all fundamental issues of human life. There are specific verses or encouraging words in Holly books that relate to any misfortune that human beings encounter in their daily life which when appropriately conveyed as condolences, reduce the pain. This finding is contrary to Al-Shboul and Maros (2013) who found reciting Quran verses as the second most frequent strategy used among Jordanians. The use of reciting Quran verses in the study appears to be motivated by respondents' strong faith in Quran as a direct word from God, revealed through Prophet Muhammad.

\section{Conclusions and Recommendations}

The study concludes that there are seven strategies of expressing condolences in Kiswahili in the context of this study ranging from the most frequently used strategy to the less frequently employed strategy as follows: asking for God's mercy and forgiveness, commenting on the deceased, expressing shock and grief, expressing sympathy, realizing death as a natural part of life, expressing skepticism and reciting some verses in Holy books.

Asking for God's mercy and forgiveness was related to participants' belief in either Christian or Islamic religion while commenting on the deceased was determined by the contribution offered by the deceased before his death. Expressing shock and grief was used to show participants' concern about the death of their president while expressing sympathy was employed to depict solidarity against the act that happened. On the other hand, participants attributed death as a natural phenomenon since it is beyond one's ability to prevent it. Moreover, expressing skepticism was used to show respondents disbelief about the death of the president while reciting some verses from Holy books was employed to show respondents' belief that the Holy books are guidelines to all fundamental issues of human life.

Further studies of similar nature are recommended to establish the role of power and social distance in the choice of condolence strategies. Similar studies can be conducted through other methods of data collection. 


\section{References}

Al-Sboul, Y \& Maros, M. (2013). Condolences Strategies by Jordanians to an Obituary Status Update on Facebook. GEMA Online ${ }^{\circledR}$ Journal of Language Studies 13(3), 151-162.

Behman, B. Hamed, L \& Asli F. (2012). An investigation of giving condolences in English and Persian via short messages. Procedia - Social and Behavioral Sciences 70 (2013) $1679-1685$.

Brown, P \& Levinson, S. (1987). Politeness: Some universals in language usage. Cambridge: Cambridge University Press.

Coates, J. (2015). Women, men and language: $A$ sociolinguistic account of gender differences in language. Routledge.

Dawtabadi, H \& Mashhadi, H. (2009). A Comparative study of Sympathy and Condolences Use by Iranian and English Native Speakers in Ceremonies: Research gate.

Egenti, M \& Mmadike, I. (2016). Speech Act Analysis of Igbo Utterances in Funeral rites. http://dx.doi.org/10.4314/og.v12i 1.3.

Elwood, K. (2004). I'm So Sorry": A Cross-Cultural Analysis of Expressions of Condolence. The Cultural Review. Studies Association Bulletin of Universities and Institutes, 24, 101-126.

Gee, J, P. (1993). An Introduction to Human Language: Fundamental Concepts in Linguistics. New Jersey: Prentice Hall.

Hancock, B, Windridge K, and Ockleford E. (2009). An Introduction to Qualitative Research. Available at https://www.rds-eastmid land.nhir.ac.uk.

Holt, E. 1993. The structure of death announcements: Looking on the bright side of death. Text 13 (2). $189-212$.

Moghaddam, M, M. (2012). Discourse structures of condolence speech act. Journal of English
Language Teaching and Learning, 10, 105125.

Neuman, W. (2014). Social Research Methods: Qualitative and Quantitative Approaches. Pearson, Essex, UK.

Nurlianingsih, D and Imperian, E. (2019). An Analysis of Condolences Speech Act by Indonesian Adolescents. International journal of Advances in Social Science, Education and Humanities Research, 430, 34-38.

Pfeiffer, C, Kleeb, M, Mbelwa, A and Ahorlu, C. (2014). The use of social media among adolescents in Dar es Salaam and Mtwara, Tanzania. Reproductive Health Matte rs 22(43):178-186.DOI:10.1016/S09688080(14)43756-X

Singh, F. (2006). Fundamental of research methodology and statistics. New Delhi, India. New age international limited, publisher.

Scollon, R. \& Scollon, S. W. 1995. Intercultural communication: A discourse approach. Oxford: Blackwell Publishers.

Walliman, N. (2006). Social Research Methods. London \& NewDelhi. SAGE Publications Ltd.

Williams, T. R. (2006). Linguistic politeness in expressing condolences: A case study. RASK: International Journal of Languages and Linguistics, 23, 45-62.

World Bank. (2020). Tanzania economic update: addressing the impact of covid-19 With a special section on the role of ICT. Available at http://www.worldbank.org/ta nza nia/economicupdate.

Yahya, E. M. (2010). A study of condolences in Iraqi Arabic with reference to English. Adab $A L$ Rafidayn, (57), 619-642.

Zunin, L. M. \& Zunin, H. S. (2007). The art of condolence. Canada: Harper Collins Publishers. 